\title{
Transgressões das regras sociais e jurídicas em Feira de Santana, 1890-1920
}

\section{Judicial and social rules transgression in Feira de Santana, 1890-1920}

Karine Teixeira Damasceno*

Resumo: As mulheres pobres, trabalhadoras e negras de Feira de Santana, entre os anos de 1890 e 1920, não produziram de próprio punho informações sobre suas vidas; por isso, os processos-crimes foram fundamentais para que pudéssemos reconstituir fragmentos de seu passado, o que nos permitiu saber, por exemplo, que elas dissimulavam e se envolviam em disputas amorosas; insistiam em fazer suas próprias escolhas sexo-afetivas e trabalhavam para garantir a própria sobrevivência e a dos seus. Algumas, ainda, transgrediam o modelo de feminilidade imposto ao se envolverem em conflitos.

Palavras chaves: mulheres pobres; trabalhadoras; negras; família

\begin{abstract}
The poor, worker and black women from Feira de Santana, between the years 1890 and 1920, did not produce information about their lives by themselves; so, the crime-processes were fundamental so that we could reconstitute fragments of their past, which allowed us to know, for example, that they dissimulated and got involved in love disputes; they insisted on making their own choice sex-affective and they worked to guarantee their own survival and the survival of their dependents. Some of them, yet, infringed the imposed feminity model when they get involved in conflicts.
\end{abstract}

Keywords: poor women; workers; blacks; family

(c) EY Direito autoral e licença de uso: Este artigo está licenciado sob uma Licença Creative Commons. Com essa licença você pode compartilhar, adaptar, para qualquer fim, desde que atribua a autoria da obra, forneça um link para a licença, e indicar se foram feitas alterações. 


\section{Apresentação}

Ao investigar as mulheres pobres, trabalhadoras e negras de Feira de Santana do final do século XIX e início do século XX, notamos que elas compartilhavam a experiência comum de ocupar um lugar social subalterno, de maneira que eram alvos preferenciais das autoridades republicanas, que, respaldadas pelo Código Penal de 1890, estavam empenhadas em disciplinar a população pobre, especialmente as mulheres. Com efeito, neste trabalho buscamos reconstituir as experiências de aproximação e diferenciação vivenciadas por nossas protagonistas e perceber como tal experiência interferia na relação com outros sujeitos sociais de Feira de Santana, entre 1890 e 1920.

Desse modo, gênero, raça e classe são os conceitos básicos que permeiam essas reflexões. Tomamos a noção de classe adotada por E. P. Thompson, na medida em que este compreende tal noção como relacional, resultado de experiências comuns herdadas ou partilhadas, de modo que as pessoas envolvidas sentem e articulam suas identidades e seus interesses diante de outros grupos com interesses divergentes. ${ }^{1}$ Nesse sentido, as mulheres de Feira de Santana que estudamos vivenciaram a condição de pobreza, lutaram para sobreviver de diferentes maneiras, no mercado formal ou informal do trabalho, e partilharam experiências comuns em seu cotidiano. ${ }^{2}$

No tocante à noção de raça, concordamos com Antonio Sérgio Alfredo Guimarães que o conceito de raça é um dos marcadores da desigualdade e da exclusão no Brasil, sendo que, no período que investigamos, tais aspectos foram presentes nas relações tanto entre os sujeitos quanto entre os grupos sociais. ${ }^{3}$ Por isso mesmo, tomamos aqui o termo "negra" como um dos sinônimos de não branca - generalização que permite associar numa mesma categoria as mulheres pardas e pretas. Este termo permite registrar a condição de subalternidade que as caracteriza, mesmo que, em muitos casos, como veremos, essas mulheres não tenham sido identificadas como "negras". Nessas situações, a análise da documentação nos permite inferir essa condição e apreender alguns de seus significados sociais.

Por sua vez, o conceito de gênero adotado aqui é inspirado na concepção defendida por Joan Scott, para quem gênero é o saber que estabelece significados para as diferenças entre mulheres e homens e que varia conforme a cultura, os grupos sociais e o tempo. Ainda de acordo com as reflexões desta autora, tal categoria sugere que as informações sobre as mulheres são necessariamente informações sobre os homens, isto é, que o estudo de um implica o estudo do outro, já que fazem parte do mesmo mundo e foram criados por ele. ${ }^{4} \mathrm{O}$ que tentamos fazer é verificar as relações que essas mulheres estabeleceram com outras mulheres e com os homens com os quais conviviam.

Por se tratar de um grupo heterogêneo, as mulheres que investigamos, em vários momentos de suas vidas, demonstraram que agiam e reagiam de 
formas diferenciadas frente aos vários desafios. Por vezes, elas demonstravam autonomia para resolver, sozinhas, seus próprios problemas, mesmo que para isso fosse preciso provocar um conflito direto, que podia incluir agressões físicas e verbais a homens ou mesmo outras mulheres, mas, dependendo da situação, elas não deixavam de enfatizar sua fragilidade e passividade ou mesmo omitir alguma informação sobre suas vidas que pudesse denunciar ou deixar transparecer que tivessem outros parâmetros de comportamento que não aqueles exigidos pelas autoridades judiciais. No entanto, isso não inviabilizava que muitas dessas mulheres compartilhassem de alguns dos valores da elite, como o desejo de um casamento oficial.

Nesse sentido, é importante ressaltar que, além das mulheres e dos homens de seu grupo social, membros de outros grupos, como patrões, fregueses abastados, e autoridades judiciais, também faziam parte de seu universo e, de forma direta ou indireta, interferiam no processo de constituição de seus papéis sociais e valores.

Com isso, não queremos dizer que essa influência fosse unilateral; ao contrário, adotamos a perspectiva de E. P. Thompson, para quem a "cultura é composta por diferentes recursos, em que há sempre uma troca entre o escrito e o oral, o dominante e o subordinado, a aldeia e a metrópole; é uma arena de elementos conflitivos". ${ }^{5}$ Da mesma forma, o conceito de circularidade cultural proposto inicialmente por Mikhail Bakhtin e desenvolvido, posteriormente, por Carlo Ginzburg também nos ajuda a entender as relações entre as pessoas com poder político e econômico e a população pobre de Feira de Santana, especialmente as mulheres. Para Ginzburg, ao analisar o contexto inquisitorial da Itália do século XVI, havia uma "influência recíproca entre a cultura das classes subalternas e a cultura dominante". ${ }^{6}$ Conforme essa perspectiva, as informações recebidas do outro grupo social eram reelaboradas de acordo com aspectos da própria cultura popular. Assim, dizer que as mulheres aqui investigadas compartilhavam alguns valores oriundos da elite não significa dizer, necessariamente, que esses valores tivessem o mesmo sentido para as elites e para as mulheres vindas da classe trabalhadora e suas famílias. Além disso, ao longo da vida, as mulheres desse grupo social vivenciavam experiências que lhes impulsionavam a transgredir determinadas regras sociais para sobreviver.

\section{Vários tipos de família, vários papéis femininos}

Ao avançarmos na análise dos processos em busca do passado das mulheres pobres, trabalhadoras e negras de Feira de Santana, outros sujeitos próximos a elas se mostraram importantes para nossa investigação. Assim, bastou puxar um fio para ouvirmos o choro alto de suas filhas e filhos pequenos, o chamado ou lamento de suas mães e pais e, por vezes, as querelas entre casais. Eis alguns desses sons. 
Em 27 de fevereiro de 1908, Maria Simplicia Bernarda do Espirito Santo, de mais ou menos 40 anos, filha de Bernardina de Tal, viúva, lavradora, analfabeta, natural de um lugar denominado Catinga, e sua filha Maria Gregoria, de mais ou menos 22 anos, solteira, lavradora, analfabeta, ambas moradoras da localidade de São José, foram até o quartel da cidade de Feira de Santana afirmando terem sido vítimas de agressão física e prestaram uma queixa contra Maria Martina. A partir do depoimento de Maria Simplicia, podemos depreender que a tensão entre as famílias havia se originado num contexto de luta pela sobrevivência, já que, segundo esta queixosa, em julho do ano anterior, três animais pertencentes a Basílio de Almeida tinham entrado em sua roça

\begin{abstract}
"[...] e fizeram bastante estrago então mandou dizer ao mesmo Basílio de Almeida que colocasse um chocalho em um burro que fazia parte dos animais acima e em resposta obteve o seguinte: o chocalho que eu tinha já botei no cavalo só se ela perguntada mandar o seu chocalho; sendo ela perguntada prejudicada em sua lavoura e não obtendo por meio brando o referido Basílio de Almeida retirar os animais da roça dela, a perguntada [ilegível] a enxotar a pau os referidos animais de dentro da sua roça ficando muito contrariada a mulher de Basílio de Almeida e prometeu depois de muita ameaça a vingasse dela perguntada e sua filha Maria Gregoria [ilegível]. No fim de julho do ano passado indo a filha dela perguntada Maria Gregoria, buscar água em uma fonte que fica próximo a morada dela perguntada e sendo de sua propriedade a mesma fonte foi sua filha Maria Gregoria surpreendida por Maria Martina, mulher de Basílio de Almeida que armada de pau vibrou uma cacetada na cabeça de Maria Gregoria e agarrando esta a jogou dentro da fonte de cabeça para baixo salvando a mesma Maria Gregoria de não morrer afogada, algumas mulheres que se achavam na ocasião na referida fonte voltando Maria Gregoria para casa e pedindo que ela perguntada a socorresse: inocentemente ela perguntada saiu armada com um pau em direção a fonte a procurar o algoz de sua filha e de facto encontrou na mesma fonte Maria Martina mulher de Basílio de Almeida e travaram-se em rasgões resultando saírem ambas com pequenos arranhões [...]".
\end{abstract}

O depoimento de Maria Simplicia possibilita a compreensão de que se tratava de uma família constituída apenas por mulheres e que elas possuíam uma pequena propriedade rural de onde tiravam seu próprio sustento. Além disso, revela tratar-se de mulheres autônomas, especialmente para resolver os problemas relacionados à sobrevivência, haja vista o conflito com a família de Maria Martina e Basílio, que, possivelmente, também possuíam uma pequena 
propriedade na qual criavam alguns animais, como as cabras citadas. $\mathrm{O}$ caso ainda nos permite observar que as três mulheres envolvidas tinham um perfil similar, pois estavam longe da passividade feminina socialmente esperada; diferentemente disso, chegavam a optar pela violência para resolver seus problemas, sendo que duas delas ainda demonstraram estarem dispostas a resolver o conflito diante da Justiça. Nesse sentido, além de confirmar a versão da mãe, Maria Gregoria ainda acrescentou que, depois desse ocorrido, ela e sua mãe foram buscar água na referida fonte e, inesperadamente, foram atacadas com um facão e cacete pelo casal e mais um neto deste, chamado Olavo. Ela ainda salientou que, antes desse episódio, já havia uma rixa entre sua mãe e a família supracitada.

Ao finalizar seu depoimento, Gregoria informou que estava "grávida" e, devido às pancadas que recebera, sentia "dores e em virtude do seu mal estar", temia que a consequência da agressão fosse a "morte de seu filho". ${ }^{8} \mathrm{Ou}$ seja, com tal informação, Maria Gregoria revela outro dado importante sobre sua vida: ela seria mãe solteira, provavelmente, pois nenhuma testemunha ou ela mesma fez qualquer referência sobre a existência de um amásio ou de relacionamentos eventuais. Essas informações nos permitem supor que, para essas personagens, outros elementos, como o fato de se relacionarem bem com a vizinhança, serem trabalhadoras e garantirem o próprio sustento realizando o pesado trabalho de lavradoras, eram considerados tão emblemáticos da respeitabilidade da mãe e da filha que tornavam desnecessários quaisquer comentários sobre a honestidade de qualquer uma delas.

Semelhante a outras mulheres encontradas, Maria Simplicia e Maria Gregoria vivenciavam um modelo de família muito comum entre os pobres tanto de Feira de Santana quanto de outras regiões do Brasil no período pesquisado, isto é, famílias chefiadas por mulheres sós. ${ }^{9}$

Por meio de outro caso acontecido um ano antes do mencionado acima, conseguimos recuperar alguns fragmentos da vida de outra família chefiada por uma mulher. As testemunhas chamadas para depor no inquérito policial sobre a morte de Maria Izabel Portugal informaram que esta residia com uma filha chamada Elane e um filho de nome Antonio Amâncio no Distrito de Humildes e trabalhava fazendo farinha. Os depoimentos das testemunhas, lavradores e moradores do mesmo Distrito, foram coincidentes. Eles ouviram da própria vítima ou de outras pessoas que ela havia se queixado de dor de dente e pretendia tomar cachaça com o objetivo de aliviar tal incômodo.

Em seu depoimento, Antonio Francisco Moreira afirmou que, ao visitar Maria Izabel, ouviu da própria "que estando com dor de dente, disse a seu filho que comprasse cânfora para deitar na aguardente, e sulimão (veneno) para as formigas e tendo os dois papéis vindos juntos, ela em vez de deitar a cânfora na aguardente, enganou-se e deitou o sulimão". ${ }^{10}$ Os depoimentos ainda foram reveladores de que Maria Izabel, preferencialmente tratada por Senhora pelos 
depoentes, era bastante estimada e querida por todos no local e que ali "muito pertinho" moravam duas irmãs da falecida. ${ }^{11}$ Dadas as condições de pobreza e a responsabilidade de trabalhadora, mãe e chefe de família, certamente, em diversos momentos da vida, Maria Izabel precisou contar tanto com a solidariedade da vizinhança quanto com a de familiares, como as irmãs citadas acima.

Em 13 de março de 1902, também no Distrito de Humildes, Adelina Maria de Jesus, de mais ou menos 30 anos, de cor branca, solteira, lavradora e analfabeta, fez uma denúncia contra Tiberio de Tal. Segundo ela, que tinha um filho pequeno,

"[...] estando em sua casa no dia quarta-feira doze do corrente às seis horas da tarde, chegou em sua porta Tiberio de Tal e convidando-a para ter com ela relações ilícitas: respondendo ela interrogada, que não aceitava pessoa de sua qualidade, quanto mais a ele; nesta resposta deu-lhe ele um sopapo que ela interrogada caiu sobre o chão; e ele Tiberio com o coice da espingarda que trazia fez-lhe as ofensas constantes do corpo de delito [...]". ${ }^{12}$

À testemunha, José Matheus de Sant'Anna, a vítima disse que Tiberio a teria assassinado se sua mãe, Bernardina de Tal, e seu pai, José Mascarenhas "não pedissem por quantos Santos há que não acabasse de matar sua filha, que a pobre da velha assim mesmo sem poder saiu empurrando ele, até que se retirou". ${ }^{13}$ A despeito da liberdade tomada por Tiberio, notamos que Adelina era respeitada por seus vizinhos, que preferiam tratá-la como Senhora, termo geralmente reservado às mulheres da elite e às mulheres casadas. Assim, ser mãe solteira, cuidar dos pais - idosos e doentes - e trabalhar para garantir a sobrevivência da família era uma postura considerada mais que suficiente para atestar a respeitabilidade de uma mulher no círculo em que convivia, tornando dispensável qualquer comentário sobre seu procedimento.

No entanto, seria ingênuo acreditar que os integrantes da população pobre estivessem alheios à ideologia do branqueamento; por isso, consideramos provável que, para as testemunhas, a distinção de cor, notadamente a valorização de indivíduos brancos, de algum modo influenciasse na imagem que construíam da vítima. Além disso, a própria afirmação desta de que o acusado era indigno de relacionar-se com ela devido a sua qualidade nos leva a pensar que provavelmente Tiberio fosse negro, o que foi determinante para que este tivesse sido desprezado. Contudo, o processo é revelador de que Adelina também estava longe de se enquadrar no perfil de submissão e de passividade considerado pelas autoridades médicas e pelos juristas como próprio de uma mulher respeitável. ${ }^{14}$ Aliás, ao que parece, tal postura diante da vida foi aprendida em casa, haja vista a intrepidez de Bernardina de Tal, que, 
mesmo já "velha" e "doente", enfrentou o agressor de sua filha, expulsando-o de casa, para defendê-la.

Outros processos nos permitem ver aspectos da vida em família de outras mulheres pobres e são elucidativos da prática de trabalho em família, especialmente entre pequenos proprietários e trabalhadores rurais. Em 12 de março de 1909, Maria Bernardina Francisca, de mais ou menos 48 anos, de cor preta, solteira, lavradora, analfabeta, natural e residente em Terra Dura, foi levada até ao quartel de Feira de Santana e, ao encontrar o Subdelegado de Polícia em exercício, Virgílio Ferreira de Caldas, prestou uma queixa contra Cirillo Teixeira de Carvalho, de 60 anos, solteiro, lavrador, natural e residente no Distrito de Humildes. Segundo ela, na

“[...] segunda-feira ao oito do corrente mês indo pisar umas manivas [mandiocas] e não podendo continuar por acha-se doente deixou de pisar, chegando nesta ocasião o dono de casa Cirillo Teixeira de Carvalho, mandando ela respondente continuar pisar as manivas, dizendo ela respondente que não podia continuar a pisar por achar-se doente, este dizendo que ela tinha manhas apoderou-se de uma vara indo contra ela respondente lhe fazendo os ferimentos constantes do corpo de delito, saindo nesta ocasião ela respondente procurando quem the acudisse pedindo misericórdia chegando sua filha que pelo amor de Deus; meu pai faça isto com minha mãe e ele Cirillo dando com a vara sem querer atender dizia hoje te mato". ${ }^{15}$

Infelizmente não foi possível saber se o casal de "amásios" tinha propriedades, mas acreditamos ser provável que as manivas tenham sido plantadas por pelo menos um deles. Além do mais, considerando uma possível divisão de tarefas entre o casal, o processo nos permitiu saber que pisar as manivas era uma das tarefas realizadas por Maria Bernardina, e certamente não era a única.

Em 12 de janeiro de 1904, Maria do Espirito Santo, de aproximadamente 30 anos, casada e moradora em Terra Dura, Distrito de São José, prestou uma queixa contra seu vizinho, Mauricio Martins da Silva, finalmente levando ao conhecimento da Justiça um conflito antigo entre ele e a vítima. Embora não tivesse presenciado o momento da agressão, Jovino Desiderio das Neves informou ter ouvido dizer que

“[...] entrando uns porcos de Maurinho [ilegível] em uma roça de Maria do Espírito Santo, conhecida por Mariquinha, indo uma criança, de cerca de seis anos, mais ou menos, filho desta, tanger da roça, com um cachorrinho os referidos animais, o denunciado penetrando na dita roça e com um 
chicote castigara a dita criança e quando Maria do Espirito Santo, despertada pelos gritos do filho, ali aparecendo foi, bruscamente, recebida pelo denunciado, que enfurecido, lançando mão de um pedaço de uma das estacas da dita cerca, virara-lhe uma cacetada partindo-lhe o braço direito". ${ }^{16}$

Antonio Florêncio Morais, outra testemunha do processo, informou que Maria era "uma senhora distinta, bem quista por todos os vizinhos, casada e deu-se esse facto, achando-se ausente seu marido pelo que andava em procura de meios para a subsistência e de sua família". ${ }^{17}$ Ao que parece, semelhante a outras mulheres pesquisadas, o cotidiano de Maria era preenchido por uma dupla jornada, já que cabia a ela cuidar de seu filho pequeno ao mesmo tempo em que tratava da roça da família, onde, provavelmente, plantavam produtos que eram usados tanto para consumo próprio quanto para serem vendidos na grande feira livre que ocorria na cidade às segundas-feiras. Enquanto isso, seu marido tentava complementar a sobrevivência familiar realizando outros trabalhos fora de casa.

O depoimento dessa testemunha ainda nos deixa ver que, embora para ele e, também para as outras pessoas mencionadas nesse estudo o casamento oficial conferisse respeitabilidade, ao enumerar as qualidades da vítima, ele mencionou outros elementos que influenciavam a caracterização de Maria como uma senhora respeitável. O depoente valorizava o fato de ela ser uma mãe zelosa ou mesmo mostrar-se autônoma no enfrentamento de situações difíceis, como diante da falta de recursos ou da necessidade de defesa de seu filho. Com efeito, ao dar vazão a toda a sua agressividade, ela demonstrou que, quando preciso, também lançava mão da violência física e, evidenciando sua identificação com outras mulheres pesquisadas, também sabia brigar, seja para defender seus filhos, seja para defender o sustento da família.

A despeito de estarmos tratando de uma documentação especializada em violência, não podemos ignorar que a agressividade era um aspecto marcante nos casos analisados. A pesquisa realizada por Maria Sylvia Carvalho Franco nos ajuda a pensar o lugar da violência na vida das mulheres e dos homens pobres de Feira de Santana na passagem do século na medida em que esta autora discute esse fenômeno. Segundo essa autora, na região do Rio de Janeiro e São Paulo do século XIX, a violência se apresentava com regularidade e atravessava toda a organização social: era uma solução padrão encontrada pelos camponeses para resolverem seus conflitos no trabalho, nos momentos de solidariedade e mesmo em ocasiões lúdicas. ${ }^{18}$

Diferentemente da conclusão à qual chegou essa autora ao analisar seu corpus documental, acreditamos que não se pode tomar a violência nos processos analisados como um padrão de comportamento dos pobres de Feira de Santana no período e nem mesmo como um padrão de comportamento 
de todos os envolvidos nos processos (réus, vítimas e testemunhas). Seus depoimentos e as versões dos fatos que apresentam fornecem elementos para pensarmos que o conflito constituía um elemento integrante das relações sociais em que viviam, mas isso não significa dizer que, na maioria das vezes, as tensões fossem resolvidas por meio da violência física. Além disso, há de se considerar que estamos analisando uma documentação repressiva e que nos permite reconstituir apenas fragmentos das vidas das pessoas envolvidas.

Pensando a violência sob a perspectiva das relações de gênero, podemos notar que, na maioria dos casos que analisamos, as mulheres apareciam como vítimas de alguma violência cometida por homens, geralmente de seus círculos de relações (companheiros e ex-companheiros ou outros conhecidos). Desse modo, assim como nos processos analisados por Franco e também por Mariza Corrêa, os casos que investigamos nos informam que algumas dessas opções violentas, a exemplo da agressão praticada por um marido ou amásio contra a mulher considerada adúltera, muitas vezes eram legitimadas pela sociedade. ${ }^{19}$ Sidney Chalhoub, por sua vez, observa que, nos casos analisados por ele, a violência do homem contra a mulher, antes de demonstrar sua força e poder, explicita sua fraqueza e impossibilidade de manter a dominação sobre esta. ${ }^{20}$ Certamente a relação de gênero entre os pobres de Feira de Santana não era diferente.

No que diz respeito à violência praticada por algumas mulheres citadas acima, observamos que Maria Simplicia, Maria Bernardina e Maria do Espírito Santo aproximam-se ainda mais, pois, diferente de outras mulheres estudadas, admitiram sua agressividade. Assim, ao defender seus interesses diante da Justiça, tentaram justificar a transgressão dos papéis sociais que lhes eram impostos utilizando o mesmo discurso empregado pelas autoridades para oprimi-las: alegaram que estavam exercendo seu principal papel como mulher, o de mãe zelosa, e, por isso mesmo, foram capazes de usar da violência para defender seus filhos da agressão de terceiros. Essa estratégia era recorrentemente utilizada pelas mulheres pobres de Feira de Santana. ${ }^{21}$ Em seu cotidiano de transgressões dos papéis socialmente admitidos para elas como veremos a seguir, essas personagens também amavam, dissimulavam e se envolviam em disputas amorosas.

\section{Mulheres casadas e mulheres amasiadas}

Em um sábado do mês de junho de 1897, por volta das 8 ou 9 horas da noite, na localidade de Baraúnas, região do subúrbio de Feira de Santana, as vozes exaltadas do casal Auta da Silva Lessa e Candido Lessa, mesmo a portas fechadas, foram ouvidas pela vizinhança. O entrevero deu origem a um processo e algumas dessas pessoas foram ouvidas pela Justiça. Em seu depoimento, Maria Antônia de Jesus, de mais ou menos 30 anos, solteira, trabalhadora doméstica, natural do Distrito de Bonfim e residente em Feira de 
Santana, informou que ela e sua filha Marta estavam em casa quando ouviram, no meio da discussão, a vítima acusar seu marido de a mandar sair para "ganhar dinheiro com outros homens para lhe dar" 22 e também dizer que iria embora de casa para nunca mais voltar. Depois dos gritos, perceberam que o casal parou de brigar de forma abrupta e a casa ficou em total silêncio. Ao informar isso, a testemunha ainda ressaltou que chegara a ficar preocupada com o que poderia ter acontecido entre o casal. ${ }^{23}$ Ao ser questionado pelo Comissário de polícia, Major José Antonio Guimarães, sobre o dia dessa briga, Candido Lessa preferiu desqualificar a companheira, que, conforme sua versão dos fatos, era uma mãe descuidada. Por isso, alegou que

“[...] no sábado do corrente sua mulher saíra de casa e foi para a casa de Eugenio, do outro lado da estrada, levando em sua companhia o menino e quando voltou estava com uma pequena contusão no rosto de uma queda que dera e ele perguntando vendo o menino com a contusão zangou-se com sua mulher e esta teimou dizendo que quando levou o menino já tinha levado a queda". ${ }^{24}$

Segundo Candido, Auta trabalhou como ajudante de cozinha em um hotel e, durante esse tempo, teve um caso com o patrão, que, por sua vez, costumava dar-lhe dinheiro; somente quatro meses antes da vítima falecer, havia conseguido convencê-la a deixar de trabalhar no hotel, mas, ainda assim, ela continuou se encontrando com o agora ex-patrão, Eugenio Penny. O caso seguiu como sumário crime, sendo que, ao invés de negar a autoria do crime, o réu investiu ainda mais, buscando demonstrar que tinha motivos legitimados pela sociedade para assassinar a esposa. Com isso, mostrou conhecer tanto as regras jurídicas quanto as regras sociais, pois alegou que, muitas vezes, flagrou a esposa em adultério "[...] e que se tivesse qualquer intenção de atentar contra ela aproveitaria a ocasião que justificaria seu crime, visto que sua honra tinha sido ultrajada [...]". ${ }^{25}$ Certamente Candido estava sendo orientado por seu advogado sobre as possibilidades de utilizar a lei a seu favor, o que, numa situação de adultério, não era algo difícil de fazer. Conforme o art. 279 do Código Penal de 1890 , não eram consideradas criminosas as pessoas que provassem privação de sentido e de inteligência ao cometerem um crime e, não por acaso, esse era um argumento frequentemente alegado pelos homens acusados de cometer alguma agressão contra companheiras ou ex-companheiras. ${ }^{26}$

Além desse aspecto da lei, que geralmente só beneficiava os homens, outros explicitam o tratamento desigual dado a mulheres e a homens. Isso não passava despercebido para os réus e seus advogados na hora de montar uma estratégia de defesa. Desse modo, ao serem acusados de cometer algum ato de violência contra suas companheiras, eles tentavam se valer tanto da legitimidade social quanto das próprias normas jurídicas. Ao acusar a vítima 
de adúltera, Candido estava lançando mão de uma tradição que legitimava a atitude do homem que lavasse sua honra com sangue se ocorresse o inverso, isto é, se ele fosse traído.

Nesse sentido, Martha de Abreu Esteves observa que os trabalhadores eram objetos de políticas públicas que visavam disciplinar a classe trabalhadora. Ademais, para os juristas, era necessário que se construísse uma legislação que fosse eficiente no sentido de controlar a sexualidade das mulheres ${ }^{27}$. Aos homens pobres também era delegado o "poder" de exercer esse controle, o que explica por que homens como Candido se agarravam a esse papel como tábua de salvação ao serem jugados por uma violência contra mulheres, fossem esposas ou amásias.

O Código Penal de 1890 tinha o objetivo de disciplinar, controlar e estabelecer normas sobre as mulheres pobres, trabalhadoras e negras para que estas assumissem as posturas desejadas, isto é, dentro do padrão de "civilidade" e digno da jovem nação republicana. Assim, suas determinações tornavam as mulheres pobres um alvo preferencial da Justiça, que era especialmente rigorosa com elas. ${ }^{28}$ Para essa discussão, é pertinente ressaltar que a desigualdade de direitos entre mulheres e homens remontava o período colonial, como destaca Keila Grinberg ao discutir o Código Civil e a cidadania no Brasil. Segundo ela, o Código Civil, aprovado em 1917, manteve, pelo menos, dois aspectos das Ordenações Filipinas que demarcavam a desigualdade de diretos entre os sexos, isto é, assim como os deficientes mentais, mendigos, menores e indígenas, as mulheres casadas continuaram sendo consideradas incapazes, enquanto que os homens eram considerados a cabeça do casal e cabia-lhes decidir sobre a vida e os bens da esposa. Além disso, manteve uma diferenciação jurídica entre as próprias mulheres, já que foi mantida a distinção entre honestas e desonestas. ${ }^{29}$ Tal tradição jurídica certamente estava relacionada à decisão das autoridades judicias de Feira de Santana de optarem por não intimar as mulheres como testemunhas, o que, por vezes, fez com que suas vozes somente fossem ouvidas por meio de uma dupla mediação, a de seus maridos e a da Justiça, sendo que, em vários outros casos, nem isso foi possível.

Além de evidenciar que Auta compartilhava com as demais mulheres pesquisadas a posição desfavorável de opressão, exclusão e invisibilidade, o processo também nos permitiu constatar que a rotina de Auta se aproximava da vivenciada por outras mulheres trabalhadoras que encontramos ao longo da pesquisa, visto que sua jornada diária não se restringia às demandas de trabalho de ajudante de cozinha no hotel, pois, conforme a tradição, as tarefas domésticas eram atribuídas às mulheres. Era muito comum que mulheres como Auta, ao findar uma longa jornada de trabalho, iniciassem outra em casa. Isto é, também nesse aspecto seu cotidiano era similar ao de outras mulheres encontradas.

As várias versões sobre o crime nos levam a acreditar que, mesmo antes de migrar para Feira de Santana, Auta já se relacionava com outros 
homens além do marido. Nesse sentido, não temos certeza se, de fato, Candido a obrigava a ter relações sexuais com outros homens, o que já o colocaria na mira das autoridades judiciais pelo crime de lenocínio ou se ela o fazia à revelia da vontade do marido. ${ }^{30}$ Porém, em todas as versões sobre esse aspecto do relacionamento do casal, foi coincidente a informação de que esses relacionamentos extraconjugais the rendiam algum dinheiro e, certamente, contribuíam para a renda familiar. Esse caso ainda nos permite pensar outro aspecto da condição das mulheres que trabalhavam como prostitutas, isto é, muitas delas sustentavam famílias inteiras com o exercício de uma atividade tão pouco honrada aos olhos das autoridades, que as perseguiam e, ao mesmo tempo, consideravam a prostituição uma ocupação necessária para a preservação da honra das mulheres honestas. ${ }^{31}$

Um aspecto que aproximava várias mulheres estudadas era a flexibilidade de suas escolhas afetivas. Para muitas delas, o casamento oficial até poderia ser um projeto de vida, mas elas não se restringiam apenas a essa possibilidade de viver o amor e o sexo. Assim como Auta, várias mulheres demonstraram possuir o casamento formal como um valor, haja vista o grande número de casadas entre as envolvidas nos processos. Contudo, por meio dos processos, também pudemos constatar que o amasiamento era muito comum entre os casais de baixa renda e bastante aceito por seu círculo de relações. As várias mulheres pobres encontradas não se furtavam a trocar um casamento formal infeliz por um amasiamento amoroso. ${ }^{32}$ Algumas delas agiram como Maria Luisa, que chegou a deixar o marido e pai de seus dois filhos para viver amasiada com outro homem. ${ }^{33}$ Esta também foi a postura de Rozalina Maria de Jesus, que admitiu ter abandonado seu marido e, demonstrando ser uma mulher fora dos padrões aceitos, viajava sozinha com um homem que não era de sua família e ainda mantinha uma relação amorosa com outro, um antigo conhecido da infância, talvez um antigo amor. ${ }^{34}$

A mesma coisa fez Antonia Maria de Jesus, de 40 anos de idade, de cor parda, solteira, lavradora, analfabeta, natural do Distrito de Pedrão e residente no Distrito de Santa Bárbara, que procurou o Subdelegado de Polícia em exercício, Capitão José Macário da Cunha, e prestou uma queixa contra seu ex-amásio, Salustiano Pereira da Silva. Segundo ela, às 5 horas da tarde, quando voltava para casa, o acusado se emparelhou com ela e, com uma foice, fez os ferimentos que apresentava; além disso, há mais de um ano ele a perseguia a fim de satisfazer seus "desejos libidinosos". ${ }^{35}$ Ao ser chamado para testemunhar sobre o caso, o lavrador e residente no mesmo distrito, Antonio Simões Lisboa, declarou que:

"[...] tendo sido Salustiano amasio de Antonia separaram a convivência, tanto que Salustiano tem hoje em sua companhia outra rapariga, entendendo que Antonia devesse se prestar para fins libidinosos como dantes, exigindo até 
que Antonia não convivesse com outro homem, e tendo ciência de que ela tinha tido uma conversação com outro em Santa Bárbara, a foi esperar em caminho exigindo que ela correspondesse a seus desejos [...]". ${ }^{36}$

Ao que parece, Antonia Maria estava decidida a não querer mais o excompanheiro e, longe da submissão tradicionalmente admitida para as mulheres, ao dizer não aos apelos sexuais de Salustiano, demonstrou uma postura de escolha: optava por viver sozinha e, quem sabe, ter outras experiências afetivas mais felizes.

Os vários casos de amasiamento encontrados nos permitem observar que uma relação conjugal informal não significava para os casais a ausência de obrigações conjugais como a fidelidade. No entanto, observamos que apenas os homens utilizaram o argumento do ciúme como justificativa para cometerem atos de violência contra suas companheiras. Ou seja, na prática, a fidelidade conjugal era uma regra de conduta exigida apenas às mulheres, fossem elas casadas oficialmente ou amasiadas.

As informações colhidas sobre as vítimas e os réus de ambos os sexos, bem como sobre as posições que ocuparam dentro do processo, nos permitem obter mais dados sobre a vida dos sujeitos, especialmente nos casos de conflitos entre casais. Por outro lado, é preciso lembrar que algumas pessoas que viviam em concubinato, ao serem indagadas sobre seu estado civil, informavam ser solteiras. Essa aparente contradição, na maioria das vezes, não tinha como objetivo a negativa da relação em si, pois, ao longo dos processos, tais informantes costumavam explicitar serem amasiados. Além disso, tal informação também era confirmada e reconhecida pelo círculo de relações dessas pessoas. Assim, para compreender esse fenômeno, é importante lembrar que os depoimentos eram transcritos pelos escrivães, que podiam traduzir uma situação vivida por meio de um termo legal.

Nesse sentido, Rachel Soihet e Martha de Abreu Esteves, ao estudarem o Rio de Janeiro da virada do século, também observaram que o amasiamento constituía uma alternativa de vida conjunta e uma prática muito comum entre as mulheres e os homens pobres. Além disso, elas observaram que, ao serem questionadas sobre o estado civil, muitas mulheres afirmaram ser solteiras, porém, ao longo de seus depoimentos, revelaram ser amasiadas. Assim, mesmo considerando a possibilidade de que, para as mulheres aqui tratadas e para as pessoas de seu grupo social, houvesse uma diferenciação entre as duas formas de união, concordamos com o argumento apresentado por Soihet de que o mais provável era que os escrivães ouvissem dos depoentes a denominação "amasiado" e traduzissem como solteiros, visto que, para os parâmetros da Justiça, só existiam três opções de estado civil - solteiro, casado e viúvo. ${ }^{37}$

Em 24 de outubro de 1906, um conflito entre moradores da localidade de Mangabeira, subúrbio da cidade de Feira de Santana, chegou ao conhecimento 
da polícia. Entre os envolvidos, encontramos a ré Maria da Anunciação, viúva, lavadeira e lavradora, analfabeta, natural e residente em Feira de Santana, e seu filho Joviniano de Cerqueira, ambos acusados pelo crime de lesão corporal em um desafeto antigo. Em seu depoimento, a vítima José Emidio de Oliveira, de mais ou menos 30 anos, solteiro, analfabeto, natural de Santo Amaro e residente em Feira de Santana, informou ao delegado que, por volta das 6 horas da tarde, no dia anterior à denúncia

"[...] estava vindo da cidade para sua casa e ao passar em frente à casa de Miguel de Tal a amásia deste que já tem uma prevenção antiga com o ofendido saiu para o lado de fora decompondo-o com palavras injuriosas e ao atracar-se com ele ofendido dera-lhe com uma preza com os dentes na bochecha do lado direito fazendo lhe o ferimento que apresenta e neste ato o filho de sua agressora de nome Joviniano de Cerqueira saiu de dentro de casa de cacete em punho e com a referida arma desprechou [sic] no ofendido a sua ira fazendo lhe os ferimentos que tem no braço esquerdo e na cabeça. Depois disto e não satisfeito ainda com o sangue que havia derramado lança a mão de uma pistola disparando no ofendido que por um verdadeiro milagre não perdeu a vida $[\ldots] "{ }^{38}$

Em seu depoimento, José Emidio ainda acrescentou que, em certo momento do conflito, a acusada o segurou para que o filho pudesse acertá-lo. Embora Maria Anunciação não tenha negado sua participação no conflito, afirmou que foi agredida por Emídio e que a intenção de seu filho foi apenas defendê-la do espancamento que ela recebia por parte do queixoso. Segundo José Conrado Ramos, a amásia da vítima saiu desesperada da Mangabeira e, por volta das 9 horas da noite, esteve em sua residência, localizada na Queimadinha, outro subúrbio da cidade, em busca de socorro. Ao ser questionado sobre o procedimento dos acusados, essa testemunha foi irônica ao responder "que para provar o bom procedimento deles, basta dizer que são avezados a prática de embriaguez", enquanto José Francisco de Paula respondeu "que os conhece mais de perto e que apenas ambos uma vez por outra se embriagam, mas que até aqui sendo seus vizinhos como são não se atreveram a encomendar-lhe nem a sua família". ${ }^{39}$.

Embora Maria Anunciação não tenha sido pronunciada, certamente o fato de ter sido levada até a Justiça nos indica que sua condição social e seus hábitos foram elementos suficientes para que o delegado considerasse prudente e educativo avaliar de forma mais minuciosa sua participação no crime, pois ela reunia vários elementos que a colocavam sob suspeição policial, já que, além de ser pobre e trabalhadora, também costumava se embriagar. 
Certamente ela não era a única mulher de seu grupo social que possuía esse perfil transgressor das regras sociais. Ao ser inquirida, a ré afirmou ser viúva, mas soubemos, por meio de algumas testemunhas, que ela vivia amasiada com um homem. Nesse aspecto, consideramos provável tratar-se de uma segunda união, que, embora fosse muito comum entre os pobres, pode, sem exagero de imaginação, ter sido considerada informação inconveniente por Maria Anunciação para ser apresentada diante da Justiça. Esse caso ainda é ilustrativo da flexibilidade quanto à forma de união conjugal entre os pobres de Feira de Santana, ou seja, um primeiro casamento oficial não queria dizer, necessariamente, que essas mulheres não viessem a estabelecer posteriormente uma relação aos moldes de um concubinato no caso de um rompimento da primeira união ou mesmo após a morte de primeiro cônjuge.

No campo das escolhas afetivas, mais uma vez notamos a complexidade desse grupo social, pois elas se diferenciavam entre si na medida em que vivenciavam diferentes modelos de experiências afetivas, isto é, encontramos mulheres solteiras, amasiadas, casadas, mas também algumas casadas ou viúvas amasiadas com outro homem. Todavia elas aproximavam-se pela repressão sofrida, expressa na tentativa da Justiça de controlar suas escolhas sexo-afetivas.

Longe de se enquadrarem no modelo de feminilidade considerado adequado para elas, as mulheres aqui tratadas viviam a experiência comum de serem subalternizadas, se não por serem negras ou trabalhadoras, com certeza por serem pobres. As histórias dessas mulheres nos deixam ver que exigir que elas fossem passivas, que frequentassem apenas o âmbito doméstico e que fossem submissas aos desejos dos homens era pedir mais do que elas poderiam ou mesmo queriam oferecer para a sociedade e para a Justiça. Como pudemos observar nos processos, mesmo aquelas mulheres que tentavam construir autorrepresentação aproximando-se dos pré-requisitos considerados adequados às mulheres não tinham condições de vida que lhes permitissem um cotidiano em consonância com todas as regras sociais e jurídicas impostas. Essas mulheres compartilhavam um conjunto de valores em que também era aceitável que elas assumissem uma postura mais autônoma diante da vida. Assim, casadas, solteiras, viúvas ou amasiadas, as mulheres que encontramos eram mulheres de luta.

\section{Considerações finais}

Com efeito, ao longo de suas vidas, a aproximação e a diferenciação entre as mulheres pobres, trabalhadoras e negras de Feira de Santana da virada do século XIX para o século XX eram construídas de diferentes modos. A maior parte delas trabalhavam para garantir a própria sobrevivência e a dos seus; eram reprimidas em suas práticas culturais; tinham um perfil autônomo diante da vida; assumiam vários papéis sociais; insistiam em fazer suas 
próprias escolhas sexo-afetivas; algumas ainda transgrediam o modelo de feminilidade imposto para elas ao se envolverem em conflitos por motivos variados.

As mulheres aqui tratadas eram alvo preferencial da Justiça. No entanto, elas não estavam alheias ao olhar disciplinador sobre elas e, por vezes, faziam escolhas diferentes para enfrentá-lo no sentido de defender seus interesses. Essas mulheres eram julgadas independentemente da posição que ocupassem nos processos - vítimas, rés ou testemunhas. Algumas pessoas de seus círculos de relações as consideravam mal procedidas, outras, bem procedidas; porém, a despeito dessas avaliações, elas não escapavam da posição de transgressoras das regras sociais e jurídicas.

\section{Notas}

* Doutoranda em História na Universidade Federal da Bahia (UFBA). Bolsista da Fundação de Amparo à Pesquisa do Estado da Bahia (FAPESB). Salvador, Bahia Brasil. E-mail: karitd@yahoo.com.br

1 THOMPSON, Edward Palmer. A formação da classe operária inglesa I: a árvore da liberdade. $4^{\mathrm{a}}$ Edição, Rio de Janeiro: Paz e Terra, 1987. p. 9-14.

2 Walter Fraga Filho, em sua análise sobre a Bahia no século XIX (Mendigos, moleques, $e$ vadios na Bahia do século XIX. São Paulo/ Salvador: HUCITEC-EDUFBA, 1996), observou que a pobreza tinha faces e gradações variadas. Assim, eram pobres os mendigos, inúmeros prestadores de serviços, vendedores ambulantes, agregados, lavadeiras, ganhadeiras, dentre outros trabalhadores que tentavam sobreviver pelas ruas de Salvador, mas também integravam essa categoria várias pessoas que tinham alguma posse, como o senhor que possuísse um escravo, alguém que fosse proprietário de um casebre, de algumas roupas ou móveis, pois estes apenas situavam-se um pouco acima da linha da miséria. (Ver especialmente p. 15-33.)

3 GUIMARÃES, Antonio Sérgio Alfredo. Classes, raças e democracia. São Paulo: Editora 34, 2002. p. 47-77.

4 SCOTT, Joan Wallach. "Prefácio a gender and politics of history", In: Cadernos Pagu Núcleo de Estudos de Gênero/UNICAMP, Campinas, n. 3, 1994. p.11-27; SCOTT, Joan. "Gênero: uma categoria útil para a análise histórica". Campinas, http://www.dhnet.org.br/ direitos/textos/generodh/gen_categoria.html. Acesso em: 04 de abril de 2011. Ver também: SCOTT, Joan. "História das mulheres". In: BURKE, Peter (Org.). A escrita da história: novas perspectivas. São Paulo: UNESP, 1992. p. 63-95 e CUNHA, Maria Clementina Pereira. "De historiadora, brasileiras e escandinavas: loucura, folias e relações de gênero no Brasil (século XIX e início do XX)”. In: Tempo, Rio de Janeiro, vol. 3, n. 5, 1998. p. 181-215.

5 THOMPSON, E. P. Costumes em comum: estudos sobre a cultura popular tradicional. São Paulo, Companhia das Letras, 1998. p. 17.

6 GINZBURG, Carlo. O queijo e os vermes: o cotidiano e as ideias de um moleiro perseguido pela inquisição. São Paulo, Companhia de Bolso, 2006. p. 18.

7 Sumário Crime. A Justiça por seu Promotor (Autor), Maria Martira (Ré). Feira de Santana-CEDOC/UEFS. Sessão Judiciária, Processos-crimes, 1908. E.02, Cx. 44, Doc. 741. fls. 7- 8.v. 
8 Sumário Crime. A Justiça por seu Promotor (Autor), Maria Martira (Ré). Feira de Santana CEDOC/UEFS. Sessão Judiciária, Processos-crimes, 1908. E.02, Cx. 44, Doc. 741. fls. 9 - 9.v.

9 Ver: DIAS, Maria Odila Leite da Silva. Quotidiano e poder: em São Paulo no século XIX. São Paulo, Brasiliense. 1995. p. 175-212. Observando São Paulo no contexto do século XIX, esta autora contribui para nosso estudo ao informar que as famílias matrifocais eram muito comuns, assim como, a existência de dependentes adultos, principalmente filhas, sendo que a unidade do grupo e a relação de solidariedade construída com a vizinhança eram atreladas à autoridade da mais velha, ou seja, mãe ou avó. Dias ainda encontrou várias famílias como a chefiada por Maria Simplicia, nas quais as filhas e, eventualmente, netos trabalhavam para auxiliar na renda familiar.

10 Inquérito Policial sobre a morte de Maria Izabel Portugal. Feira de Santana - CEDOC/ UEFS. Sessão Judiciária, Processos-crimes, 1907. E. 04, Cx. 102, Doc. 2128. fls. 7.

11 Inquérito Policial sobre a morte de Maria Izabel Portugal. Feira de Santana - CEDOC/ UEFS. Sessão Judiciária, Processos-crimes, 1907.E. 04, Cx. 102, Doc. 2128. fls. 11-12.

12 Sumário Crime. A Justiça por seu Promotor (Autor), Tiberio Machado da Costa (Vítima). Feira de Santana - CEDOC/UEFS.Sessão Judiciária, Processos-crimes, 1908. E. 03, Cx. 72, Doc. 1369. fls. 7-7.v.

13 Sumário Crime. A Justiça por seu Promotor (Autor), Tiberio Machado da Costa (Vítima). Feira de Santana - CEDOC/UEFS. Sessão Judiciária, Processos-crimes, 1908. fls. 9.v - 11.

14 SOIHET, Rachel. Condição feminina e formas de violência: mulheres pobres e ordem urbana 1890-1920. Rio de Janeiro, Forense Universitária, 1989. p 189.

15 Sumário Crime. A Justiça Pública por seu Promotor (Autor), Cyrillo Teixeira Carvalho (Réu). Feira de Santana - CEDOC/UEFS. Sessão Judiciária, Processos-crimes, 1909. E. 02, Cx. 51, Doc. 854. fls. 7-8.

16 Denúncia. A Justiça pública por seu Promotor (Autor), Mauricio Martins da Silva (Réu). Feira de Santana - CEDOC/UEFS. Sessão Judiciária, Processos-crimes, 1904.E. 01, Cx. 26, Doc. 478. fls. 21-v.22.

17 Denúncia. A Justiça pública por seu Promotor (Autor), Mauricio Martins da Silva (Réu). Feira de Santana - CEDOC/UEFS. Sessão Judiciária, Processos-crimes, 1904. E. 01, Cx. 26, Doc. 478. fls. 22.v - 24.

18 FRANCO, Maria Sylvia de Carvalho. Homens livres na ordem escravista. São Paulo: UNESP, 1997. p. 9-63.

19 CORRÊA, Mariza. Morte em família: representações jurídicas de papéis sexuais. Rio de Janeiro, Graal, 1983.

20 CHALHOUB, Sidney. Trabalho, lar e botequim: o cotidiano dos trabalhadores no Rio de Janeiro da belle époque. $2^{\mathrm{a}}$ Edição, Campinas-SP, Editora da UNICAMP, 2001. p. 171-246.

21 CORRÊA, Mariza. Morte em família: representações jurídicas de papéis sexuais. Rio de Janeiro, Graal, 1983; DAVIS, Natalie Zemon. Histórias de perdão: e seus narradores na França do século XVI. São Paulo, Companhia das Letras, 2001. Estas autoras fazem uma discussão interessante sobre a dificuldade para construir uma narrativa de defesa das mulheres em um processo judicial.

22 Tribunal de Apelação. A Justiça Pública por seu Promotor (Autor), Candido Lessa (Réu). Feira de Santana - CEDOC/UEFS. Sessão Judiciária, Processos-crimes, 1901. E. 04, Cx. 97, Doc. 2031. fls. 22.v - 24 . 
23 Tribunal de Apelação. A Justiça Pública por seu Promotor (Autor), Candido Lessa (Réu). Feira de Santana - CEDOC/UEFS. Sessão Judiciária, Processos-crimes, 1901. E. 04, Cx. 97, Doc. 2031. fls. 22.v - 24.

24 Tribunal de Apelação. A Justiça Pública por seu Promotor (Autor), Candido Lessa (Réu). Feira de Santana - CEDOC/UEFS. Sessão Judiciária, Processos-crimes, 1901. E. 04, Cx. 97, Doc. 2031. fls. 16-17.

25 Tribunal de Apelação. A Justiça Pública por seu Promotor (Autor), Candido Lessa (Réu). Feira de Santana - CEDOC/UEFS.Sessão Judiciária, Processos-crimes, 1901. E. 04, Cx. 97, Doc. 2031. fls. 58-60.

26 Código Penal Brasileiro (Decreto n. 846 de 11 de outubro de 1890) comentado por Oscar de Macedo Soares. Brasília: Senado Federal, 2004. CORRÊA, Mariza. Morte em família: representações jurídicas de papéis sexuais. Rio de Janeiro, Graal, 1983.

27 ESTEVES, Martha de Abreu. Meninas perdidas: os populares e o cotidiano do amor no Rio de Janeiro da Belle Époque. Rio de Janeiro, Paz e Terra, 1989. p. 25-36.

28 Nestas obras podemos conhecer discussões similares ao apresentado por Martha de Abreu Esteves. SOIHET, Rachel. Condição feminina e formas de violência: mulheres pobres e ordem urbana 1890-1920. Rio de Janeiro, Forense Universitária, 1989. p. 278-279; FAUSTO, Boris. Crime e cotidiano: a criminalidade em São Paulo (1880-1924), São Paulo, EDUSP, 2001. p. 82.

29 Sobre a discussão, esta autora também informa que tanto nas Ordenações Filipinas quanto no Código Civil de 1917 eram consideradas desonestas as mulheres que não casavam virgens, podendo ser deserdadas por seus pais como punição e ter o casamento anulado. No tocante aos filhos legítimos e ilegítimos, ela destaca que estes só poderiam ser reconhecidos pelo pai após a morte da primeira esposa, isso se o pai viesse a casar-se com a mãe. GRINBERG, Keila. Código Civil e Cidadania. Rio de Janeiro, ZAHAR, 2008. p. 43-47.

30 SCHETTINI, Cristiana. "Que tenhas teu corpo”: uma história social da prostituição no Rio de Janeiro das primeiras décadas republicanas. Rio de Janeiro, Arquivo Nacional, 2006.

31 SOIHET, Rachel. Condição feminina e formas de violência: mulheres pobres e ordem urbana 1890-1920. Rio de Janeiro, Forense Universitária, 1989. p. 200.222.

32 ESTEVES, Martha de Abreu. Meninas perdidas: os populares e o cotidiano do amor no Rio de Janeiro da Belle Époque. Rio de Janeiro, Paz e Terra, 1989.

33 Sumário Crime. Justiça Pública por seu Promotor (Autor), Manuel dos Santos (Réu).Feira de Santana - CEDOC/UEFS. Sessão Judiciária, Processos-crimes, 1903. E. 02, Cx. 49, Doc. 821. fls. 10.v-11.v.

34 Denúncia. A Justiça por seu Promotor (Autor), Rozalina Maria de Jesus (Ré). Feira de Santana-CEDOC/UEFS. Sessão Judiciária, Processos-crimes, 1913. E. 01, Cx. 12, Doc. 235. (O processo deu continuidade e aparece até o ano de 1924).

35 Denúncia. A Justiça pública por seu Promotor (Autor), Salustiano Pereira Araujo ( Réu). Feira de Santana-CEDOC/UEFS. Sessão Judiciária, Processos-crimes, 1910. E. 01, Cx. 13, Doc. 251. fls.3-3.v.

36 Denúncia. A Justiça pública por seu Promotor (Autor), Salustiano Pereira Araujo ( Réu). Feira de Santana-CEDOC/UEFS. Sessão Judiciária, Processos-crimes, 1910. E. 01, Cx. 13, Doc. 251. fls. 14-15. 
37 ESTEVES, Martha de Abreu. Meninas perdidas: os populares e o cotidiano do amor no Rio de Janeiro da Belle Époque. Rio de Janeiro, Paz e Terra, 1989; SOIHET, Rachel. Condição feminina e formas de violência: mulheres pobres e ordem urbana 1890-1920. Rio de Janeiro, Forense Universitária, 1989; SOIHET, Rachel. "Mulheres pobres e violência no Brasil urbano": In: PRIORE, Del Mary. (Org.). História das Mulheres no Brasil, São Paulo, Contexto, 1997. p. 367-370.

38 Denuncia. A Justiça pública por seu Promotor (Autor), Maria Anunciação e Joviniano de Cerqueira (Réus). Feira de Santana - CEDOC/UEFS. Sessão Judiciária, Processos-crimes, 1906. E. 02, Cx. 33, Doc. 569. fls. 6-7.

39 Denuncia. A Justiça pública por seu Promotor (Autor), Maria Anunciação e Joviniano de Cerqueira (Réus). Feira de Santana - CEDOC/UEFS. Sessão Judiciária, Processos-crimes, 1906. E.02, Cx. 33, Doc. 569. fls. 14-15.

Recebido em: 15/09/2017

Aprovado em: 03/12/2017 